\title{
Implicaciones anestésicas en el síndrome de Larsen: a propósito de un caso
}

Jarana Aparicio I, Díaz Lara M.D., Bonilla García J.L.

Hospital Juan Ramón Jiménez, Huelva.

\section{Resumen}

El síndrome de Larsen (SL) es una enfermedad hereditaria rara caracterizada por un defecto en la formación de colágeno debido a mutaciones en los genes que codifican la proteína citoesquelética filamina B. Su prevalencia en Europa es aproximadamente de 1/250.000 nacidos vivos. Esto implica una serie de rasgos y particularidades anatómicas de la vía aérea que debemos valorar en niños que van a ser sometidos a un acto anestésico.

Se presenta el caso de un niño de 11 años diagnosticado de síndrome de Larsen que se interviene de aticotomía oído izquierdo. A este propósito, realizamos revisión bibliográfica sobre las peculiaridades del manejo anestésico de estos pacientes.

\section{Introducción}

El síndrome de Larsen (SL) es una enfermedad hereditaria rara caracterizada por un defecto en la formación de colágeno debido a mutaciones en los genes que codifican la proteína citoesquelética filamina $\mathrm{B}$. $\mathrm{Su}$ prevalencia en Europa es aproximadamente de 1/250.000 nacidos vivos. Esto implica una serie de rasgos y particularidades anatómicas de la vía aérea que debemos valorar en niños que van a ser sometidos a un acto anestésico.

Se presenta el caso de un niño de 11 años diagnosticado de síndrome de Larsen que se interviene de aticotomía oído izquierdo. A este propósito, realizamos revisión bibliográfica sobre las peculiaridades del manejo anestésico de estos pacientes.

\section{Caso Clínico. Material y Métodos}

Varón de 11 años con luxación congénita de caderas y rodillas, pies equinovaros e intervenido previamente de paladar hendido y hernia inguinal derecha. No tenía antecedentes de estridor, disnea o síncope.

A la inspección, tenía una cara pequeña $\mathrm{y}$ plana con una frente prominente $\mathrm{y}$ distancia intercantal ancha. Respecto a vía aérea, Mallampati clase II.

No presentaba anomalías vertebrales, confirmado radiológicamente.

No hubo evidencia de ningún defecto cardíaco y su electrocardiograma y ecografía transtorácica era normal. El niño fue intervenido de colesteatoma congénito izquierdo (aticotomía oído izquierdo).

Fue premedicado con Midazolam intravenoso $3 \mathrm{mg}$ antes de entrar en el quirófano, revisando previamente el carro de la vía aérea difícil. Colocación 
cuidadosa en la mesa de quirófano con protección de decúbitos. Monitorización estándar (frecuencia cardíaca, presión arterial no invasiva, ECG, pulsioximetría) así como BIS. La inducción fue realizada con Sevoflurano $7 \%$ con $100 \%$ de oxígeno, Atropina 0.3 $\mathrm{mg}$, Fentanilo $60 \mathrm{mcg}$ y $25 \mathrm{mg}$ de Rocuronio. Una vez alcanzada una profundidad anestésica adecuada, se aseguró la vía aérea con tubo anillado $\left(\mathrm{n}^{\circ} 6\right)$. Tras ello, se administró un bolo de $40 \mathrm{mg}$ de Metilprednisolona para evitar posible edema postintubación. La anestesia se mantuvo con Sevoflurano (concentración alveolar mínima 1) y Fentanilo. El paciente permaneció estable hemodinámicamente durante la cirugía que duró $120 \mathrm{~min}$. El rescate analgésico se hizo con Paracetamol 450 mg, Nolotil $1200 \mathrm{mg}$ y Ondansetrón 3 mg. Se extubó al paciente sin incidencias y se trasladó a Reanimación. El postoperatorio inmediato transcurrió también sin incidencias.

\section{Discusión. Resultados}

El Síndrome de Larsen se caracteriza por una serie de alteraciones esqueléticas: luxaciones congénitas de grandes articulaciones

(predominantemente rodillas y caderas), anomalías craneofaciales (frente prominente, puente nasal hundido, región mediofacial aplanada e hipertelorismo ocular), deformidades en la columna vertebral tales como cifosis, escoliosis, vértebras múltiples e inestabilidad, en ocasiones asociadas a mielopatía cervical y falanges distales cortas, anchas y en forma de espátula, con el pulgar casi siempre afectado.

Sin embargo, las implicaciones anestésicas se derivan fundamentalmente de tres circunstancias: las anormalidades de la musculatura lisa del tracto respiratorio que puede dar lugar a una importante laringotraqueomalacia, los defectos cardiovasculares (sobre todo en los tabiques interauriculares e interventriculares, dilatación e insuficiencia aórtica y prolapso e insuficiencia de la válvula mitral) y las anomalías espinales.

Ya en 1971 Latta et al. describieron las alteraciones de vía aérea en este síndrome reportando el caso de un paciente con laringotraqueomalacia que ellos atribuyeron a una falta de rigidez del cartílago laríngeo y traqueal debido a un defecto subyacente. Desde entonces, los problemas en la vía aérea han sido descritos frecuentemente como parte de este síndrome. Esta circunstancia puede ser una amenaza vital para el paciente que se exacerba por ejemplo con el edema producido por infecciones del tracto respiratorio y tras la intubación endotraqueal. Además, como la vía aérea distal también puede verse afectada, el cuadro no siempre es solucionable mediante traqueostomía.

La función respiratoria en el postoperatorio también puede verse comprometida por la propia broncomalacia, que puede desembocar en atelectasias y un mayor riesgo de neumonía. A veces podría recomendarse fisioterapia respiratoria en el perioperatorio, así como ventilación mecánica más prolongada.

Además de laringotraqueomalacia, puede ocurrir una estenosis subglótica. Para evitarlo es de utilidad revisar registros de actos anestésicos previos para ver el tamaño del tubo utilizado. Si la estenosis subglótica es conocida, un ciclo previo de corticoides ayudaría a prevenir el edema postintubación. De todos modos, siempre que sea posible la intubación debe ser evitada, prefiriéndose el uso de dispositivos supraglóticos.

En 1975, Swensson et al. describieron por primera vez las alteraciones 
cardiovasculares asociadas al SL. Presentan el caso de un niño de 5 años que desarrolló dilatación del cayado aórtico e insuficiencia aórtica con regurgitación similar a la que se observa en los pacientes con síndrome de Marfan. Se ha puesto de manifiesto que los defectos cardiovasculares son más prevalentes en las formas autosómicas recesivas que en las dominantes. Debido a la relativa alta frecuencia de anomalías cardíacas, el ecocardiograma está indicado como parte del estudio preanestésico en pacientes que presentan soplos.

La otra circunstancia que puede repercutir en el acto anestésico son las anomalías de la columna vertebral. Es muy frecuente que estos pacientes presenten cifoescoliosis de la columna cervical y torácica debido a alteraciones en los cuerpos vertebrales. Estas anomalías a nivel cervical obligan a que la instrumentación de la vía aérea deba ser muy cuidadosa, por lo que su manejo se asemeja al de un paciente con daño vertebral a ese nivel. Es importante evitar la excesiva hipertextensión cervical durante la intubación.

No debe usarse succinilcolina como relajante muscular puesto que puede producir mielopatía cervical con debilidad muscular distal que predispone a hiperpotasemia. El compromiso de los músculos abdominales e intercostales puede desembocar en fallo respiratorio durante el postoperatorio.

La mayoría de estos niños presentan un coeficiente intelectual normal y con las correcciones ortopédicas adecuadas durante la infancia pueden llevar a cabo una vida normal en muchos de los casos.

\section{Conclusión}

El síndrome de Larsen es una enfermedad rara que implica una serie de particularidades anatómicas de la vía aérea que debemos valorar en niños que van a ser sometidos a un acto anestésico, dichas particularidades radican principalmente en anormalidades de la musculatura lisa del tracto respiratorio (laringotraqueomalacia), defectos cardiovasculares (sobre todo en los tabiques interauriculares e interventriculares, dilatación e insuficiencia aórtica y prolapso e insuficiencia de la válvula mitral) y anomalías espinales.

\section{Imágenes}

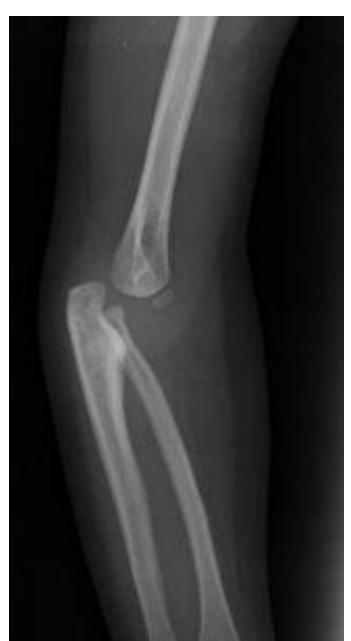

Imagen 1. Luxación de codo. 


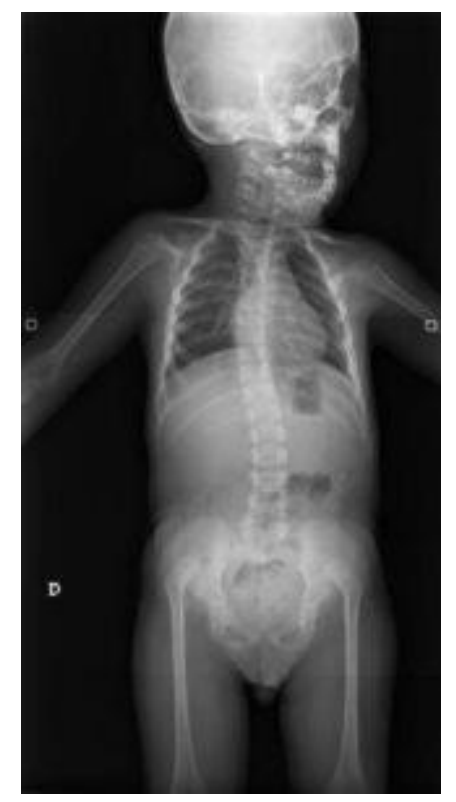

Imagen 2. Escoliosis lumbar y luxación congénita de cadera.

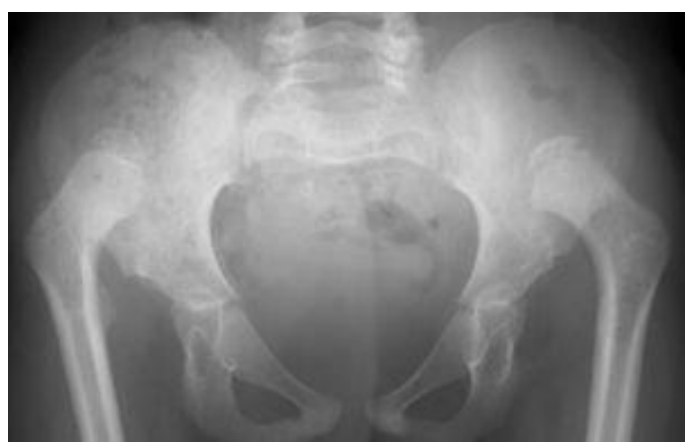

Imagen 3. Luxación congénita de cadera.

\section{Bibliografía}

1. Amit Rai, Anjan Trikha, Ashish Kumar, Ravindran Chandran. Supraglottic airway and caudal epidural for anesthetic management of a child with Larsen syndrome. Journal of Anaesthesiology Clinical Pharmacology | AprilJune 2016 | Vol 32 | Issue 2 (MC)
2. M.A. Castellano del Castillo, F. Pombo Taboada, M.A. Blanco Ramos, M. Pérez gay. Hematoma postraumático en síndrome de Larsen asociado a déficit de factores VII y X de la coagulación. Rehabilitación (Madr) 2003;37(2):113-5.

3. Austin J, Ali T. Tracheomalacia and bronchomalacia in children: Pathophysiology, assessment, treatment and anaesthesia management. Paediatr Anaesth 2003;13:3-11. (PubMed)

4. Saricaoglu F, Dal D. Cardiac arrest in a patient with Larsen syndrome under sevoflurane anesthesia. Paediatr Anaesth 2004;14:889. (PDF)

5. Tobias JD. Anesthetic implications of Larsen syndrome. J Clin Anesth 1996;8:255-7. (PubMed) ( $\underline{\text { HTML) }}$

6. Larsen LJ, Schottstaedt ER, Bost FC. Multiple congenital dislocations associated with characteristic facial abnormality. J Pediatr 1950;37:574-81. (PubMed)

Correspondencia al autor

Irene Jarana Aparicio

jarana.irene@hotmail.com

MIR Anestesia. Hospital Juan Ramón Jiménez, Huelva.

Aceptado para el blog en mayo de 2019. 